Original paper

\title{
Feeding behavior of the urchin-eating urchin Salmacis sphaeroides
}

\section{Makoto TSUCHIYA $^{1, *}$, Moritaka NISHIHIRA ${ }^{1, * *}$, Suree POUNG-IN ${ }^{2, * * *}$, and Surapon CHOOHABANDIT $^{3}$}

${ }^{1}$ Faculty of Science, University of the Ryukyus, Nishihara, Okinawa 903-0213, Japan

${ }^{2}$ Department of Marine Sciences, Chulalongkorn University, Bangkok 10500, Thailand

${ }^{3}$ Sichang Marine Science Training Station, Chulalongkorn University, Sichang, Cholburi 13345, Thailand

* Corresponding author: M. Tsuchiya

E-mail: tsuchiya@sci.u-ryukyu.ac.jp

** Present address

General Research Center, Ocean Exposition Commemorative Park Management Foundation, Motobu, Okinawa 9050206, Japan

*** Present address

Phuket Marine Biological Center, Phuket 80300, Thailand

Communicated by Makoto Tsuchiya

Abstract On the shallow sandy bottom in the innermost part of the Gulf of Thailand, the regular sea urchin Salmacis sphaeroides feeds on two spatangoid urchins: Brissus latecarinatus, one of the locally dominant infaunal macrobenthic animals, and Lovenia elongata. Aggregations of Salmacis were frequently seen on the soft bottom during a survey of the macrobenthos in the Gulf, and Brissus individuals lacking spines were found beneath the aggregations. Brissus species, which are infaunal, were attacked by Salmacis, although the reason for their presence on top of the sandy bottom remains unknown. Salmacis were seen feeding first on the spines of Brissus, exposing the test. Occasionally, Salmacis carrying empty, broken tests of Brissus were observed, indicating that the Brissus organs were also eaten by Salmacis. The fact that Salmacis ate several kinds of food items such as water hyacinths originated from the nearby river system, sea pens, jellyfish, and other urchins indicates that this species is an omnivore. Cannibalism was also found both in the field and laboratory. The feeding strategy of
Salmacis has evolved to incorporate diverse food items, but Brissus is undoubtedly an important food source because of its high abundance.

Keywords Salmacis sphaeroides, Brissus latecarinatus, predation, Gulf of Thailand, feeding strategy

\section{Introduction}

Predation is one of the most important factors controlling community structure in natural ecosystems, and the importance of predator-prey interactions between infauna and epifauna on marine soft-bottom communities has been specifically emphasized (Schrijvers et al. 1998; Quijón and Snelgrove 2005; Beseres and Feller 2007).

We found a fact that the regular sea urchin Salmacis sphaeroides feeds on two spatangoid urchins: Brissus latecarinatus, one of the locally dominant infaunal macro- 
benthic animals, and Lovenia elongata on the sandy bottom of the inner part of the Gulf of Thailand. Although consumption of sea urchins by some predators has been reported (Moitoza and Phillips 1979; Cowan 1983; Tegner and Levin 1983), reports of urchins preying on other urchin species are rare; in fact, this is only the second record of an urchin-eating urchin. The green urchin Strongylocentrotus droebachiensis preyed on the sand dollar Echinarachnius parma on the coast of Newfoundland, Canada (Himmerlman and Steele 1971). Here, we report the feeding habits of the urchin-eating urchin Salmacis sphaeroides.

\section{Study area and methods}

The surveys were conducted around the Sichang Islands, the innermost part of the Gulf of Thailand $\left(13^{\circ} 09^{\prime} \mathrm{N}, 100^{\circ} 48^{\prime} \mathrm{E}\right)$, in 1984, 1987, 1994, and 1997. The shallow subtidal area of this region can be divided into three subzones according to the distribution pattern of macrobenthic animals and substrate characteristics (Tsuchiya et al. 1986). The shallowest zone consists of a rocky or sandy coast, the second zone is occupied by hermatypic corals dominated by the massive coral Porites lutea (coral zone), and the third zone is characterized by a soft bottom extending to deeper areas with conspicuous surface irregularities resulting from the feeding activity of Brissus. A transect line was placed perpendicular to the shoreline from the intertidal zone, and a general survey of the macrobenthic animals was conducted along the line.

Feeding activities of Salmacis on Brissus were observed both in the field and in the laboratory. In the field, a Brissus was dug from the sediments and put on different substrates such as sandy particles and gravels. Then, several Salmacis specimens were arranged to surround the Brissus.

Cage experiments were also conducted to observe the feeding behavior of Salmacis. Hemisphere type plastic cages with $5 \mathrm{~mm}$ mesh were used for experiments conducted in the habitat of Brissus. Six experimental treatments were tested. In all treatments, five individuals of Brissus were introduced to the cages and the behavior of Salmacis was monitored for one week.

\section{Results and discussion}

Sea urchins were abundant on the soft bottom. The most abundant epifaunal urchin species was Diadema setosum, but its distribution area was restricted to the shallower two subzones (Tsuchiya et al. 1986). A high abundance of Brissus was marked along the transect line within $0-50 \mathrm{~m}$ from the lower limit of the coral zone (70 $\mathrm{m}$ from the shoreline), showing a peak abundance $\left(>100\right.$ individuals $\left./ \mathrm{m}^{2}\right)$ at approximately $35 \mathrm{~m}$ (ca. $2 \mathrm{~m}$ deep from the lowest low waters, LLW) (Choonhabandit and Tsuchiya 1989). The distribution area of Salmacis (density: 0-5 individulas $/ \mathrm{m}^{2}$ ) overlapped considerably with that of Brissus, but no Salmacis were found in the 0-15 m region, suggesting that there may be an interspecific interaction between the two species. Temnopleurus toreumaticus, which is closely related to Salmacis, was found in the deeper area $(>100 \mathrm{~m})$. Lovenia was found mainly in the deeper zone, indicating habitat segregation with Brissus.

In these zones, predation on Brissus (Fig. 1a) by Salmacis was frequently observed and dead Brissus individuals lacking spines (Fig. 1b) or its empty shells were common on the sandy bottom surface. Salmacis was also feeding on Lovenia (Fig. 1c). Other items such as the water hyacinth (Fig. 1d) and sea pen (Fig. 1e) were also eaten.

Many potential food items are carried to this area because of its locality in the innermost part of the Gulf of Thailand. Some terrestrial and freshwater plant species are frequently carried to the Gulf and seen on the bottom. Vascular plants including Ipomoea, Wedelia, Eichorrnia, Leucaena, and unidentified grasses, banana skin, dried beef, and salami were artificially placed separately at sites along the line at 5,15,25, and $35 \mathrm{~m}$ from the lower limit of the coral zone. Salmacis feeding was observed in all cases, suggesting that Salmacis is a generalist feeder and can use a diversity of food items that may show temporal variation. In addition, cannibalism among Salmacis was observed in the laboratory.

Six individuals of Salmacis were placed around a Brissus (ca. $10 \mathrm{~cm}$ in distance), and the behavior of two 

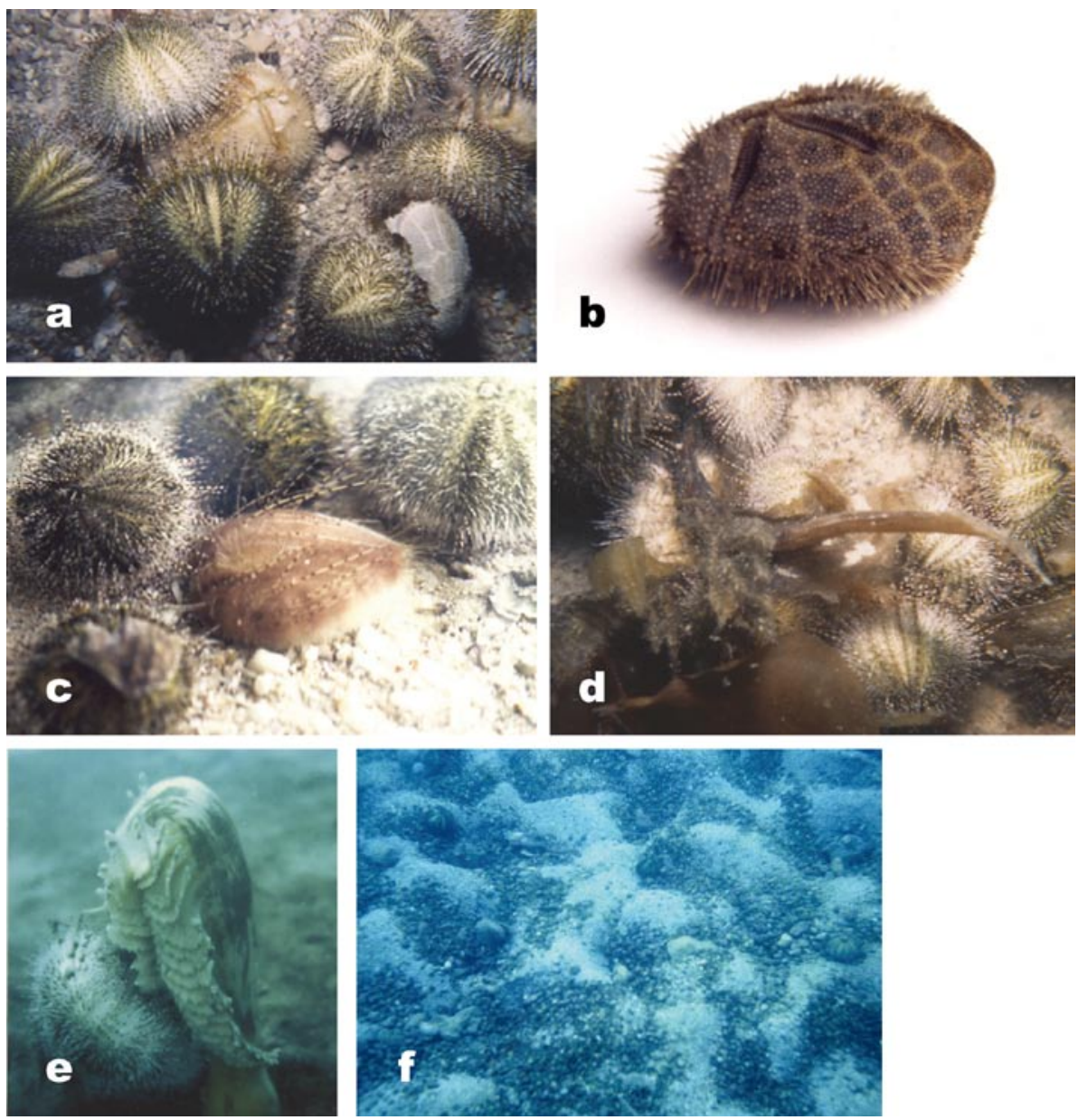

Fig. 1 a) Several individuals of the sea urchin Salmacis sphaeroides feeding on the spatangoid Brissus latecarinatus (center top) in the gulf of Thailand. One individual is carrying an empty test of Brissus (right bottom), b) Brissus of which most spines were eaten by Salmacis, c) Salmacis attacking Lovenia elongata., d) Salmacis feeding on the water hyacinth carried from the nearby river system, e) Salmacis feeding on a sea pen, and f) Environmental heterogeneity (surface irregularity) of the habitat of Brissus

species were continuously monitored. One minute after setting, one Salmacis began to move toward the Brissus, in only $10 \mathrm{sec}$, reached and rode on the Brissus. The second Salmacis followed the first one showing similar behavior, reached and contacted with the first Salmacis. Both Salmacis performed spine waving, an intraspecific interaction. At the same time, another Salmacis also moved toward the aggregation, but voluntarily left the experimental area. The Brissus began to burrow into the sediment $5 \mathrm{~min}$ after the first Salmacis arrived, and half of its body was hidden in the sediment after $15 \mathrm{~min}$. Other Salmacis joined the aggregation within 15-18 min, and two individuals left the aggregation after 20 and $24 \mathrm{~min}$, respectively. After $38 \mathrm{~min}$, the Brissus completely es- caped into the sediment. Damage to the Brissus did not appear serious. We conducted similar experiments on different sediment conditions (i.e. on gravel and sandy bottoms) and observed the predation process by Salmacis. Brissus only escaped from its predators when on a sandy bottom. It could not escape from attacking predator probably because of burrowing difficulty on gravel substrates. Therefore, environmental heterogeneity resulting from the mosaic distribution of sediments (Fig. 1f) can contribute to the survival of both Brissus and Salmacis.

This was confirmed by the cage experiments in the field (Fig. 2). In Treatment 1, five Brissus were placed on the net installed just beneath the bottom surface, thus, all Brissus could not burrow and remained exposed on the 


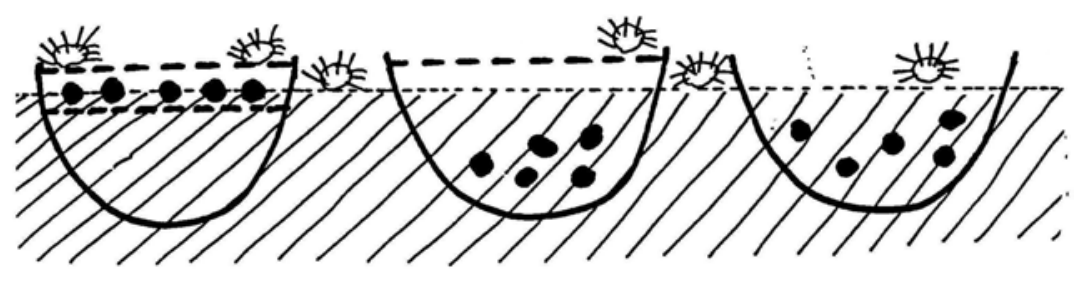

Treatment 1

Treatment 2

Treatment 3

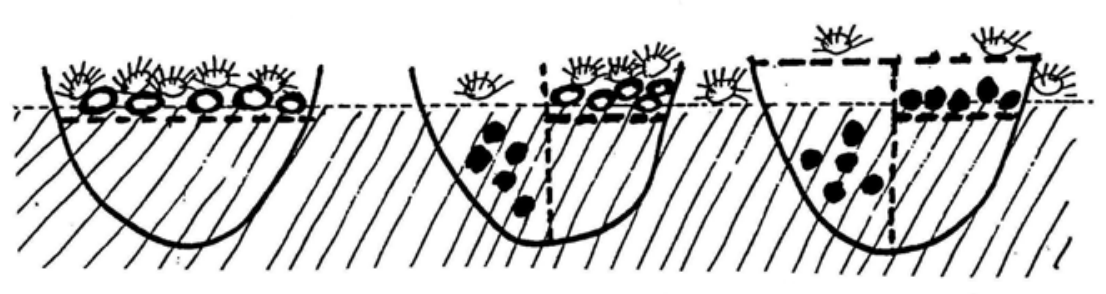

Treatment 4

Treatment 5

Treatment 6

Fig. 2 Experimental design for observing of the predation on Brissus laticarinatus by Salmacis sphaeroides. Hemisphere type plastic cages, about $50 \mathrm{~cm}$ diameter with $5 \mathrm{~mm}$ mesh were used. Six treatments were prepared by installing the net in two ways: just beneath sediment surface to block Brissus from burrowing, and on the cage top to prevent invasion of Salmacina into the cage. By different combination of setting these two nets, 6 treatments were tested. Cages were set buried in the substrates in the field, as is shown here. Five Brissus were introduced in a cage in Treatments 1 to 4, and each 5 individuals in both sectors in Treatments 5 and 6, and the survival of Brissus (closed circles) and interaction with Salmacis (open circles with spines) were monitored

sediment surface. Another net was fit above the Brissus, Salmacis came and tried to intrude into the cage, but could not attack the Brissus and all Brissus could survive during the experimental period. When the net inside the cage in Treatment 1 was removed, Brissus burrowed deep into sediments and become imvisible from the surface (Treatment 2, all Brissus survived). Some Salmacis were seen on and around the cage. Treatment 3 was conducted without a net both in and top of the cage. Although Salmacis could invade the cage, Brissus placed on the bottom surface burrowed into the sediments and all escaped from the predation by Salmacis. In Treatments 4 and 5, Brissus which could not burrow into sediments due to obstruction by the net, were attacked by Salmacis and died. When the net was set above the Brissus they were not attacked by Salmacis. Treatment 5 is a combination of treatment 3 and 4 in a cage, and Treatment 6 the combination of Treatments 1 and 2. Treatments 5 and 6 showed the same results that were found in Treatments 1 to 4 . All the findings suggest that, for Brissus, burrowing in the sediment is only the way to escape from the predation by Salmacis.

The Brissus population can be divided into two sub- populations by body size, with the near-shore sub-population including large specimens and the offshore subpopulation including smaller individuals. The density was higher offshore (Maximum: 126 inds. $/ \mathrm{m}^{2}$ ) than nearshore $\left(17.8\right.$ inds. $\left./ \mathrm{m}^{2}\right)$, and the grain size distribution of the habitat also differed (Tsuchiya et al. 1989). Sediments inhabited by the near-shore population are clearly a mosaic of gravels and sand particles created by the feeding activity of Brissus, while the offshore area was consistently sandy. However, there is a possibility that the difference in grain size composition affects the population density; the sandy bottom may accelerate population growth, because of the easiness in escape into the sediments. On gravel substrates, Brissus has difficulty escaping from Salmacis when Brissus appeared on the surface, resulting in a lower density than in the deeper zone.

Tsuchiya et al. (1989) studied the recolonization process of Brissus in the urchin-free area (removed area) and counted a high density of ca. 50 individuals $/ \mathrm{m}^{2} 2$ weeks after the depopulation. This suggests that Brissus continually look for their new habitat and sometimes appear on the sediment surface. This must be a good chance for Salmacis to prey on their food. Brissus ap- 
pearance on the sediment surface might be a result of self-thinning of the Brissus population according to the intraspecific competition in the high density area. If so, the thinning effect also contributes to the survival of the other species, Salmacis. It is still unknown, however, why Brissus appears on the sediment surface in its low density zone.

A huge population of Brissus has been providing a considerable food source for Salmacis, and the coexistence of both species can be maintained by the environmental heterogeneity of the soft bottom. This heterogeneity also helps maintain the high species diversity of the infaunal community, as community structure differs among environments (Tsuchiya et al. 1989).

\section{Acknowledgments}

This paper is dedicated to the late professor Kiyoshi Yamazato who was a pioneer of the cooperative research program between University of the Ryukyus, Japan, and Chulalongkorn University, Thailand. We sincerely thank Drs. P. Menasveta and J. Padermsak, Aquatic Resource Research Institute, Chulalongkorn University, for their help in the field work in the Gulf of Thailand and Dr. M. Shigei who kindly identified the sea urchin species. The National Research Council of Thailand (NRCT) allowed us to study the benthic communities in the Gulf of Thailand. This study was supported by grants for the oversea research (Nos. 62041072 and 63043058), and partially supported by a grant for the 21st Century COE program "The Comprehensive Analyses on Biodiversity in Coral Reef and Island Ecosystems in Asian and Pacific Regions" from the Ministry of Education, Culture, Sports, Science and Technology, Japan.

\section{References}

Beseres JJ, Feller RJ (2007) Importance of predation by white shrimp Litopenaeus setiferus on estuarine subtidal macrobenthos. J Exp Mar Biol Ecol 344: 193-205

Choonhabandit S, Tsuchiya M (1989) Ecological distribution of shallow subtidal macrobenthic animals on the sandy bottom of Sichang Island, the Gulf of Thailand: A preliminary report. Galaxea 8: 231-239

Cowan RK (1983) The effect of sheephead (Semicossyphus pulcher) predation on red sea urchin (Strongylocentrotus fraciscanus) population: an experimental analysis. J Exp Mar Biol Ecol 58: 249-255

Himmerlman JH, Steele DH (1971) Foods and predators of the green sea urchin Strongylocentrotus droebachiensis in Newfoundland waters. Mar Biol 9: 315-322

Moitoza DJ, Phillips DW (1979) Prey defence, predator preference, and nonrandom diet: the interactions between Psycnopodia helianthoides and two species of sea urchins. Mar Biol 53: 299-304

Quijón PA, Snelgrove PVR (2005) Differential regulatory roles of crustacean predators in a sub-arctic, soft-sediment system. Mar Ecol Prog Ser 285: 137-149

Schrijvers J, Camargo MG, Pratiwi R, Vincx M (1998) The indfaunal macrobenthos under East African Ceriops tagal mangroves impacted by epibenthos. J Exp Mar Biol Ecol 222: 175-193

Tegner MJ, Levin LA (1983) Spiny lobsters and sea urchins: analysis of a predator-prey interaction. J Exp Mar Biol Ecol 73: 125-150

Tsuchiya M, Nakasone Y, Moordee R, Manthachitra V (1986) Distribution of subtidal macrobenthic animals around the Sichang Islands, the Gulf of Thiland. Galaxea 5: 75-96

Tsuchiya M, Nishihira M, Choohabandit S, Poung-In S (1989) Environmetnal heterogeneity created by the spatangoid urchin Brissus latevcarinatus and its effect on sandy bottom communities in the Gulf of Thailand. Galaxea 8: 241255

Received: 28 August 2009

Accepted: 22 October 2009

(C) Japanese Coral Reef Society 